https://artnodes.uoc.edu

\title{
El viaje in situ. De cómo el caminar en espacios confinados puede potenciar la imaginación
}

\section{Laura Apolonio \\ Universidad de Granada}

Fecha de presentación: septiembre de 2020

Fecha de aceptación: diciembre de 2020

Fecha de publicación: enero de 2021

\section{Cita recomendada}

Apolonio, Laura. 2021. «El viaje in situ. De cómo el caminar en espacios confinados puede potenciar la imaginación». En: Benítez, Laura; Berger, Erich (coord.). «Artes en tiempos de pandemia». Artnodes, N. ${ }^{0}$ 27: 1-9. UOC. [Consulta: dd/mm/aa]. http://doi.org/10.7238/a.v0i27.373921

(c) SOMTERIGHISRESERVED
Los textos publicados en esta revista están sujetos -si no se indica lo contrario- a una licencia de Reconocimiento 4.0 Internacional de CreativeCommons. La licencia completa se puede consultar en https://creativecommons.org/licenses/by/4.0/deed.es_ES.

\section{Resumen}

Durante la pandemia de COVID-19 nos hemos encontrado de repente confinados en casa, reducidos a una mínima interacción social y un limitado desplazamiento físico. Con este artículo queremos mostrar cómo esta condición reductiva del confinamiento puede revertirse y transformarse en un recurso que potencia la creatividad. Partiendo de ejemplos históricos (como el viaje recluido en su habitación de Xavier de Maistre) y artísticos (desde Francis Alÿs a William Kentridge, Francesco Careri y otros colectivos artísticos contemporáneos) y basándonos en investigaciones antropológicas (David Le Breton) y neurológicas (Shane 0'Mara), mostraremos cómo la simple actividad de caminar tiene una increíble capacidad de estimular nuestra creatividad, abriendo en nosotros un espacio infinito -nuestra imaginación- que representa una zona de libertad siempre a nuestro alcance. Concluiremos, junto con Didi-Huberman y Tim Ingold, en la necesidad de rescatar nuestra facultad imaginativa que, contrariamente a lo que se piensa, no nos aleja de la realidad, sino que nace precisamente de una atenta observación y un sumergirnos en su densidad para despertar el deseo de transformación. 


\title{
artnodes
}

https://artnodes.uoc.edu

El viaje in situ. De cómo el caminar en espacios confinados pueden potenciar la imaginación

\section{Palabras clave}

confinamiento, pandemia, caminar, imaginación, creatividad.

\author{
The journey in situ. \\ How walking in confined spaces can boost imagination
}

\begin{abstract}
During the COVID-19 pandemic we found ourselves suddenly confined at home, reduced to minimal social interaction and limited physical displacement. With this article we want to show how this reductive condition of confinement can be reversed and transformed into a resource that enhances creativity. Starting from historical examples (such as Xavier de Maistre's journey to his room) and artistic ones (from Francis Alÿs to William Kentridge, Francesco Careri and other contemporary artistic collectives) and based on anthropological (David Le Breton) and neurological (Shane O'Mara) research works, we will show how the simple activity of walking has an incredible capacity to stimulate our creativity by opening in us an infinite space - our imagination - that represents a zone of freedom always within our reach. We will conclude, together with Didi-Huberman and Tim Ingold, with the need to rescue our imaginative faculty which, contrary to what is thought, does not distance us from reality, but originates precisely from careful observation and immersion in its density to awaken the desire for transformation.
\end{abstract}

\section{Keywords}

confinement, pandemic, walking, imagination, creativity

Partiendo de la situación de confinamiento impuesta por la pandemia de COVID-19, nuestra intención es investigar sus consecuencias en la producción artística. Nuestra hipótesis es que la reducción física del territorio no siempre implica una aminoración creativa, sino que, al contrario y sorprendentemente, puede representar un estímulo para la imaginación, sobre todo si va unida a la actividad física de caminar.

\section{Viaje alrededor de una habitación}

A finales del siglo xix el escritor Xavier de Maistre, exiliado en Turín, fue condenado a arresto domiciliario por cuarenta y dos días por haber participado en un duelo prohibido. En lugar de sentirse apenado por esta reclusión forzosa, descubre el nuevo placer de viajar por el «charmant pays de l'imagination» (el encantador país de la imaginación ${ }^{1}$ ) (Maistre, 1829: 123). La experiencia le produce tal disfrute y enriquecimiento personal que escribe el libro Voyage autour de ma chambre (1829) (Viaje alrededor de mi habitación) para compartir con el público lo que para él es «une ressource assurée contre l'ennui» (un recurso seguro contra el aburrimiento) (Maistre, 1829: 2). Se siente muy orgulloso de su descubrimiento, ya que el tipo de viaje que propone es independiente de la fortuna, resistente a la intemperie, indiferente a la envidia ajena y proporciona una dicha infalible para cualquier persona. Así emprende su viaje de cuarenta y dos días -los de su reclusión-, correspondientes a los cuarenta y dos capítulos del libro, en el que viaja con su «habit de voyage»-su ropa de estar por casa-con la que camina «de découvertes en découvertess (de descubrimiento en descubrimiento) (Maistre, 1829: 36), recorriendo su habitación, pasando por la cama, el sillón, el pasillo de los retratos, el escritorio, la biblioteca, la ventana... y en cada lugar piensa, recuerda, medita, sueña. Sigue movimientos aleatorios, rectos, circulares, diagonales y en zigzag, sin ninguna regla, como el ajetreo de pensamientos que lo asaltan a cada segundo. Descubre, de este modo, el inmenso espacio de la imaginación y la ensoñación, «ce vaste espace toujours ouvert devant moß» (este vasto espacio siempre abierto ante mí), una libertad interior que es inextinguible. Así concluye al final del libro:

Ils m'ont défendu de parcourir une ville, un point; mais ils m'ont laissé l'univers entier: l'immensité et l'éternité sont à mes ordres. [...]. Était-ce donc pour me punir qu'on m'avait relégué dans ma chambre? - dans cette contrée délicieuse qui renferme tous les biens et toutes les richesses du monde? (Me han prohibido recorrer una ciudad, un punto; pero me han dejado el universo entero: la inmensidad y la eternidad están a mis órdenes. [...] ¿Es para castigarme que me habían relegado en mi habitación, en esta deliciosa comarca que contiene todos los bienes y todas las riquezas del mundo?) (Maistre, 1829: 124).

1.Todas las traducciones entre paréntesis de las citas son de la autora. 


\section{artnodes}

https://artnodes.uoc.edu

Enrique Vila-Matas rememora el viaje de Xavier de Maistre y Io relaciona con el cuento El Aleph, en el que Borges relata el descubrimiento de una pequeña esfera mágica que condensa en ella la totalidad del universo, donde «cada cosa es infinitas cosas» porque se ve «desde todos los puntos del universo» (Borges, 2015: 205). Este punto en el que confluyen todos los puntos del espacio cósmico es la capacidad de nuestra consciencia de abrirse a todas las posibilidades. Escribe Vila-Matas (2010): «No lo dudemos más. Desde nuestro cuarto habitual, sin salir a calle alguna, nos ha sido dado el gran don (que tantas veces olvidamos) de ver la esfera que permite ver la simultaneidad del universo». Este don es la imaginación que nos hace viajar a velocidad instantánea por un país inmensamente vasto sin límites ni de espacio ni de tiempo. Es un pozo inagotable de recursos y riquezas interiores que nos brinda una libertad, una vía de escape que nos puede salvar de cualquier situación.

David Le Breton, en su obra Éloge de la marche (2000), dedica un capítulo a la peculiar marcha inmóvil de Xavier de Maistre mostrando cómo un caminante no necesita una vasta geografía para pasear, ya que puede «réenchanter» (reencantar) con una geografía interior una inmovilización forzada (Le Breton, 2000: 59-61). En su último libro Marcher la vie (Le Breton, 2020) reitera el potencial liberatorio de la marcha citando el ejemplo de Nelson Mandela, que recorría cada día varios kilómetros en su celda para «reprendre corps dans son existence» (retomar cuerpo en su existencia) (Le Breton, 2020: cap. 1). Todo el libro está dedicado a evidenciar el poder curativo del caminar.

\section{El camino de Santiago en una habitación}

El potencial creativo de la interrelación entre caminar/reclusión/ imaginación se encuentra también en la obra Albert's way que Francis Alÿs realizó para la exposición On the Road (Moure, 2014) que reunió obras de destacados artistas de arte contemporáneo en una gran conmemoración de la figura de san Francisco de Asís, no solo como personaje histórico que emprendió hace ochos siglos el viaje de Asís a Santiago de Compostela, sino, y sobre todo, por la actualidad de las ideas que subyacen a su actitud, como la dignidad de la pobreza, el viaje o la errancia inherente a la condición humana y el caminar como vía de conocimiento. Francis Alÿs creó una obra especialmente para la ocasión en la que se filmó a sí mismo recorriendo 118 km -la distancia equivalente al Camino Inglés, desde Ferrol a Santiago de Compostela- entre las cuatro paredes de su estudio, caminando en círculos. Su caminata rítmica, pausada y constante se grabó utilizando cámaras posicionadas en distintos lugares del estudio. El cortometraje de esta grabación puede verse en la web del artista (Alÿs, 2014) (figura 1).

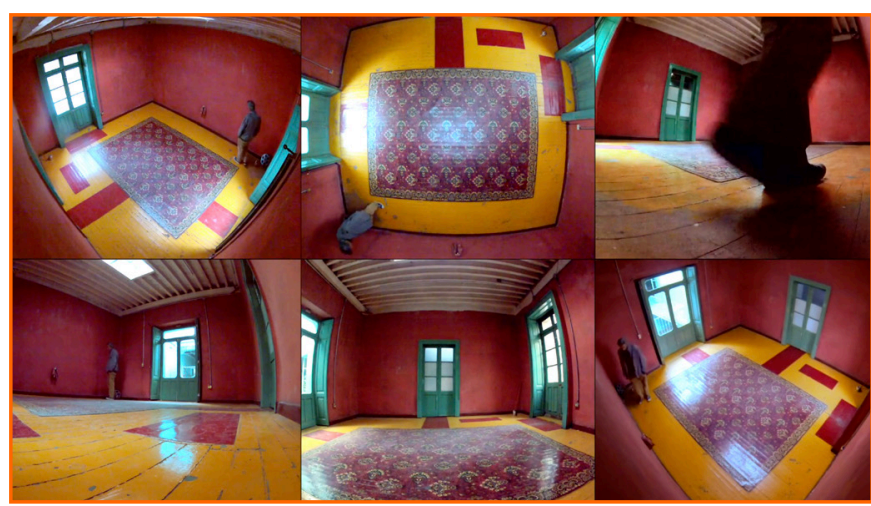

Figura 1. Francis Alÿs: Albert's way (@Francis Alÿs)

Esta caminata, transformada en una especie de procesión ritual con el paso siempre ritmado por una zancada regular y nunca alterado por obstáculos exteriores, es una metáfora del lento camino ascético del peregrino que acepta tácitamente su condena de ser humano incompleto y pacientemente emprende el ritual que mantiene viva su esperanza de salvación. Es, por lo tanto, un elogio a la espiritualidad intrínseca del ser humano y una reflexión sobre el caminar como acto de consciencia. Pero con la referencia en el título a Albert Speer, Alÿs Ileva el contexto de la peregrinación mucho más allá, transformándola en un acto de liberación y supervivencia mental. Albert Speer, el arquitecto de Hitler, fue condenado en el juicio de Núremberg a veinte años de cárcel. Al inicio del vídeo, un texto nos informa sobre la intenciones de Alÿs en su performance: «Durante 7 días desde las 9 hasta las 7 caminaré en mi estudio una distancia equivalente a la ruta del Camino Inglés, la ruta de $118 \mathrm{~km}$ que recorren los peregrinos desde el puerto de Ferrol en la costa atlántica hasta la ciudad santa de Santiago de Compostela» y añade: «Se rumorea que, cuando estaba encarcelado en Spandau, Albert Speer caminaba en círculos por el patio de la prisión midiendo con sus pasos la distancia exacta de una ciudad a otra imaginando los lugares por los que pasaría a lo largo de su viaje virtual alrededor del mundo». Speer caminó alrededor de su celda rememorando todos los espacios reales que recorrió en su vida. Llegó a caminar más de $30.000 \mathrm{~km}$ por una geografía imaginaria que se había construido midiendo cuidadosamente la geografía real. Cuando fue liberado, se encontraba imaginariamente en México cerca de Guadalajara (Kitchen, 2015: 316-325). Una geografía imaginaria le abría así un espacio infinito que traspasaba las paredes de la celda y le otorgaba la fuerza para seguir caminando y resistir a la reclusión. El caminar, por otro lado, le proporcionaba el movimiento físico y ritual que le permitía conectar con su imaginación y escapar mentalmente a su condición aprisionada. La obra de Alÿs invita a reflexionar sobre el poder espiritual del caminar y la estrecha unión entre el andar y el imaginar. 


\section{artnodes}

\section{Derivas en el estudio, una procrastinación productiva}

Para el artista William Kentridge caminar en círculos en su estudio tiene un poderoso efecto creativo. Este movimiento circular es lo que hace brotar las ideas. En la XLIV Conferencia del Museo Sigmund Freud de Viena, Kentridge afirma que caminar dando vueltas en el microcosmos del estudio -entre bocetos, fotos, fragmentos de ideas, trabajos empezados, proyectos abandonados, etc.- da lugar a una especie de «pensamiento periférico» particularmente fructífero (Kentridge, 2017). Se entra en un vórtice pensativo en el que se mezclan los fragmentos visuales de las paredes del estudio con pensamientos actuales y así se va forjando la energía que hace surgir las ideas. Es una manera de focalizar el pensamiento nutriéndose de elementos aleatorios relacionados. Para Kentridge, la categoría de Io provisional, de la ambigüedad, de la paradoja, se encuentra en el «borde» del mundo, no en el centro, y es una zona muy fértil para la creatividad. Por esto es tan importante para él esta caminata circular en el estudio porque descentralizamos la mente, la abrimos a todas las sugerencias «periféricas» $y$, al mismo tiempo, la enfocamos hacia el centro.

En otra conferencia impartida en la Universidad de 0xford (mayo 2013), Kentridge elogia la caminata en círculo dentro del estudio definiéndola «a productive procastination» (una procrastinación productiva), un esperar en movimiento, reuniendo la energía, las vagas nociones flotando en los bordes, hasta llegar al momento de clarividencia, el instante en el que el impulso creativo activa el carboncillo o la tinta que tocan el papel y empieza el proceso artístico. Para el artista, este milagro creativo es debido precisamente a la actividad física del caminar. Así lo expresa:

There is something in the physical activity of the walk, something in the activity of falling and catching yourself, which is the activity of walking, the repetition of the weight changing from the left leg to the right leg and back, that shakes one's brain, that allows ideas to emerge, that for me never come if I am simply sitting and waiting. (Hay algo en la actividad física de la caminata, en la acción de caer y reincorporarse en el caminar, en la repetición del cambio de peso de la pierna izquierda a la derecha y viceversa, que sacude el cerebro, permite que las ideas surjan, que para mí nunca vienen si simplemente estoy sentado y esperando).

Más adelante reflexiona sobre la diferencia entre caminar en línea recta en la playa y caminar en círculos en el estudio. Mientras que en la primera avanzamos hacia una meta, en la segunda no vamos a ninguna parte, es un viaje in situ. Volvemos continuamente al mismo lugar, no cambiamos nunca de posición y esta repetición circular sin fin, este movimiento dinámico y estático a la vez tiene, según Kentridge, una especie de empuje narrativo como si, en la siguiente ronda del estudio, la idea estuviera ahí («a kind of narrative push, as if the next round of the studio, the idea will be there»).
Kentridge termina su conferencia con una divertida animación titulada Taking a lion for a walk (sacar a un león de paseo), una clara referencia a la famosa expresión de Paul Klee «line on a walk» (línea de paseo) (Klee, 1960: 16). El artista reemplaza line (línea) por lion (león), que en inglés tiene una pronunciación parecida, añadiendo una pizca de humor y una alusión a otro elemento clave en la creación: el error o la confusión. En la animación se sitúa a sí mismo caminando de un lado a otro entre las páginas de un libro como un león enjaulado, buscando la idea que representa su libertad de expresión. El caminar en círculo se revela, una vez más, como una estrategia liberatoria para que las ideas cobren vida y escapen de la «jaula» mental de los prejuicios (figura 2).

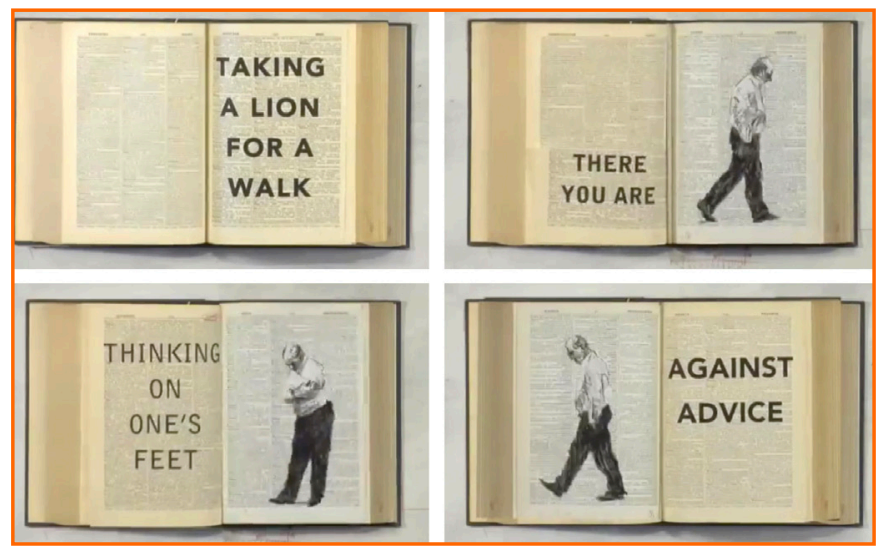

Figura 2. William Kentridge: Taking a lion for a walk (@Kentridge)

\section{Caminar dentro de un copo de nieve}

Walkspace es un colectivo de escritores y artistas de Birmingham (Inglaterra) que, como declaran en su web (2020a), investigan cualquier forma de caminar, desde un simple paseo a la más «dura» (hardcore) psicogeografía. Afirman que «There are no right or wrong ways to go for a walk but there are definitely ways to make them curious and enlightening» (No hay maneras correctas 0 incorrectas de dar un paseo, pero definitivamente hay maneras de hacerlos curiosos y reveladores). Durante el confinamiento, en el que solo estaba permitido caminar en una zona limitada, han desarrollado un interesante proyecto llamado Extreme Noticing under Lockdown, or how to launch a walking collective during a pandemic (Extrema atención bajo confinamiento, o cómo fundar un colectivo de caminantes en tiempos de pandemia). En el vídeo explicativo del proyecto (Walkspace, 2020b) utilizan la metáfora del copo de nieve o estrella de Koch para explicar que la realidad puede dividirse en unidades cada vez más pequeñas, revelando así su naturaleza caleidoscópica que eclosiona en un sinfín de detalles, descubriendo su continuo potencial para sorprender 


\section{artnodes}

y maravillar. La lógica constructiva del copo de nieve de Koch se basa en una continua división de triángulos que genera una serie infinita de estrellas que es ilimitada, aunque se mantenga siempre dentro de los límites de un círculo (figura 3).

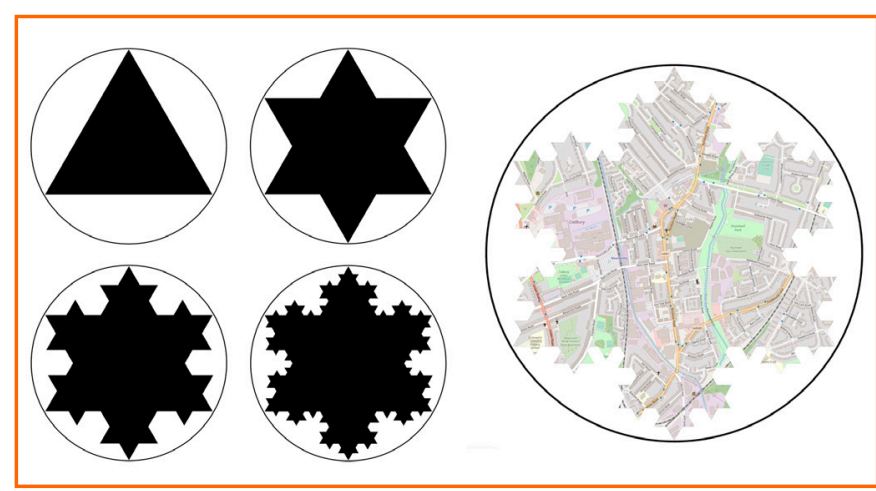

Figura 3. Estrella de Koch y zona limitada de confinamiento (@Walkspace, 2020).

Aplicando esta misma lógica al mapa restringido de los paseos permitidos durante el confinamiento, el colectivo Walkspace se planteó obtener el mismo efecto mágicamente fractal en el territorio circunscrito que tenía a su alcance y, al mismo tiempo, conseguir involucrar a un público numeroso en una experiencia colectiva formada por paseos solitarios. Se dieron cuenta de que las caminatas en territorios limitados en realidad no tenían límites y que podían seguir descubriendo nuevos detalles y asombrarse hasta el infinito. Inventaron, de este modo, un método de paseo basado en lo que llamaron Extreme notice (extrema atención). En el vídeo Extreme noticing under Lockdown (2020b) exponen las condiciones necesarias para poder realizarlo con éxito: 1) extrema familiaridad con una zona; 2) incapacidad de abandonar esa zona; 3 ) instrucciones de caminar al aire libre todos los días en esa misma zona; 4) una mente correctamente sintonizada. Una vez reunidas todas estas condiciones, lo único que tenemos que hacer es caminar por la misma ruta durante una o dos semanas y notar todo lo que nos llame la atención. Según los testigos en el vídeo, la experiencia ha sido absolutamente reveladora. La gente descubrió en su barrio zonas que no imaginaba que podían existir. Así lo expresa un testimonio: «It was like going through the doors of perception, like a whole other world existed in the place I had lived for 30 years. Everywhere I looked there was something news (Era como traspasar las puertas de la percepción, como si otro mundo existiera en el lugar en el que he vivido durante 30 años. Dondequiera que mirara había algo nuevo).

Todas las experiencias se subieron a un mapa interactivo (Walkspace, 2020c), un proyecto on-going que permanece abierto, invitando a cada participante a compartir sus asombrosos descubrimientos. En él se encuentran fotos tan singulares como una rueda de bicicleta en un árbol, un dinosaurio (juguete) en la acera, una misteriosa caja negra, un sendero bautizado «sendero del deseo», etc. El objetivo es recalcar la diversidad del barrio y de sus habitantes, no caer en la uniformidad de los mapas impuestos por fines comerciales, no perder la atención hacia lo extraño, volver a sentir el estupor de los niños, reaprender a maravillarse por lo insignificante. Es lo que Perec llama «l'infra-ordinaire» (lo infraordinario), título de su famoso libro, en el que se propone mirar con atención e interrogar «ce qui se passe chaque jour et qui revient chaque jour, le banal, le quotidien, l'évident, le commun, l'ordinaire, l'infra-ordinaire, le bruit de fond, I'habituel... (lo que ocurre cada día y vuelve cada día, lo banal, lo cotidiano, lo evidente, lo común, lo ordinario, lo infra-ordinario, el ruido de fondo, lo habitual...) (Perec, 1989: cap.1). Así mantenemos viva nuestra creatividad -directamente ligada a la curiosidad y a la capacidad de asombro- y nos aseguramos la supervivencia dentro de la cautividad, encontramos una escapatoria, en sentido literal o metafórico, de un confinamiento real o del cautiverio alegórico de la gris rutina cotidiana que nos mantiene en una especie de anestesia que nos impide prestar atención a lo que nos rodea.

\section{Planisferoom: el mundo entero en una habitación}

Para el arquitecto Francesco Careri, autor del libro Walkscapes, el andar como práctica estética (2017), la mejor manera de prestar atención a nuestro entorno es caminar lentamente y dejarse ir a la deriva. Para él, el andar es un instrumento de conocimiento, de contacto real con el territorio y quienes lo habitan, un método procesual que ayuda a deshacernos de prejuicios, afrontando cualquier proyecto desde la humildad de nuestra condición corporal. Su asignatura de arte público -que ha preferido renombrar "Arte Cívico» porque sostiene que el arte público es principalmente un arte relacional- se imparte enteramente caminando, explorando los «vacíos urbanos» 0 «amnesias urbanas» (Careri, 2017: 153), es decir, los no lugares, las zonas que se han creado espontáneamente en los intersticios del plan urbanístico y que representan los territorios todavía vírgenes por descubrir.

Durante la pandemia, la prohibición de salir le obligó a recluirse en casa y solo podía dar clases online. Frente al impedimento de caminar, en una situación de implosión territorial, se le ocurrió una idea. Cogió todos los mapas de los lugares que había visitado a lo largo de su vida, que guardaba encerrados en una caja, y decidió desplegarlos por toda la casa, llenando así paredes, suelo, mesas, sofás, sillas, etc., incluso los tendió en el tendedero como si fueran ropa lavada, evocando así un singular proceso de «muda de piel» (figura 4). 


\section{artnodes}
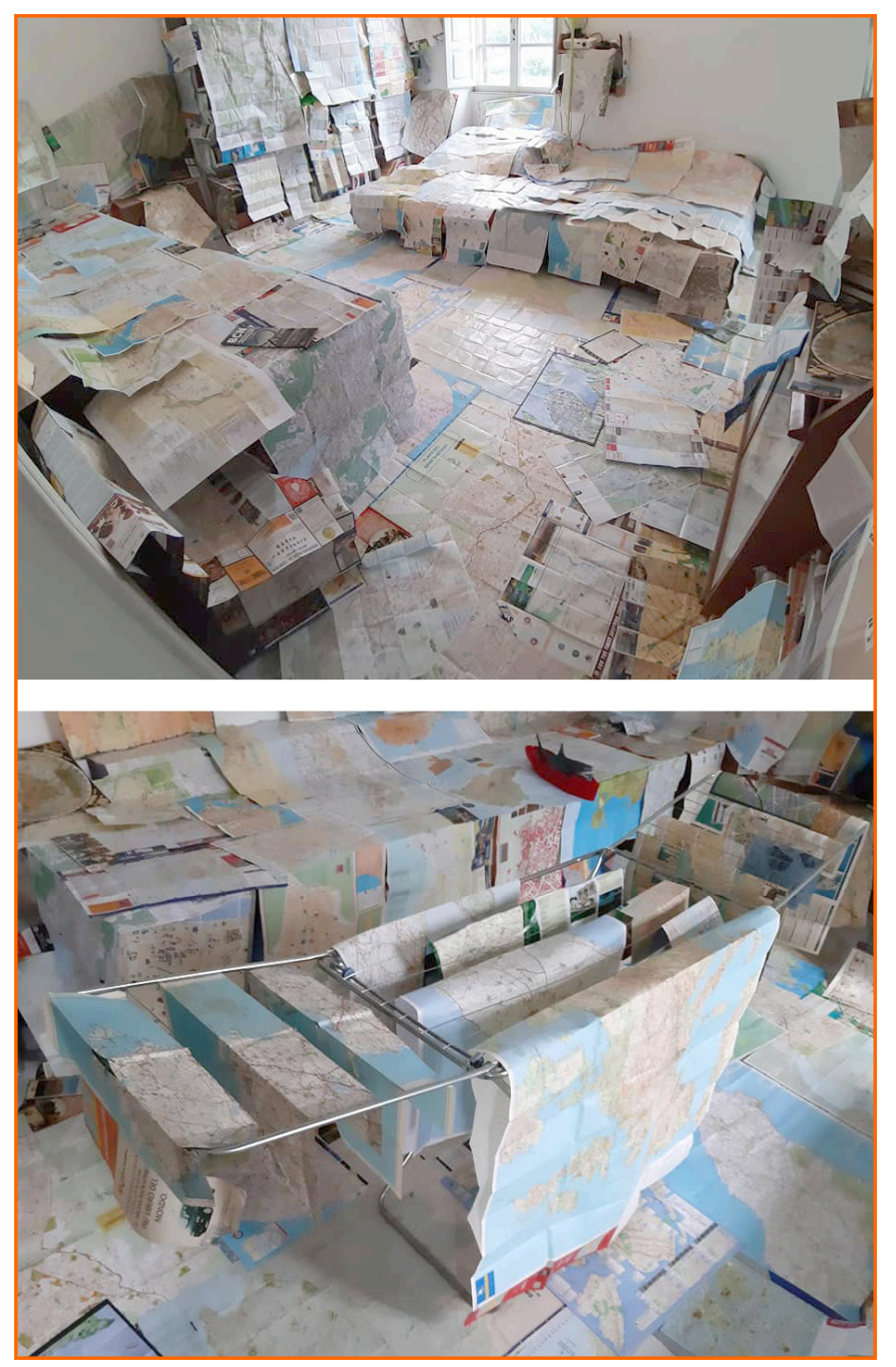

Figura 4. Francesco Careri: Planisferoom (@ Careri, 2020)

Así nació su nuevo proyecto que tituló primero Di-Stanza -que en italiano es un juego de palabra entre «distanciamiento» (distanza) y «habitación» (stanza) - y que después sustituyó por Planisferoom, más internacionalmente inteligible. «Es para escaparme -declara en una conversación con el arquitecto Germán Valenzuela (Careri, 2020) - y para acordarme de todos los lugares donde he estado». Confiesa que tiene una verdadera pasión por los mapas y que cada vez que visita un nuevo lugar, ciudad, región o país, siempre se lleva un mapa de recuerdo. «Ahora con el confinamiento tienes que viajar en tu cuarto", añade Careri e invita a todos los que lo están escuchando a hacer lo mismo en sus casas. «Después podremos viajar entre todos con nuestros cuartos conectados.» Nace, de este modo, este nuevo proyecto que representa una invitación a viajar mentalmente, «en la geografía de la cuarentena», como explica Careri, utilizando los mapas como trampolín de exploración, estímulo para la curiosidad y el deseo de conocer, imaginar, soñar... Es una reflexión sobre la cartografía, la inevitable brecha entre sus códigos y la realidad, pero también de cómo en sus pliegues se encuentra el inagotable potencial del despliegue de la imaginación. Como escribe Deleuze, «tout se plie, se déplie, se replie» (todo se pliega, se despliega y se repliega) en la correspondencia entre los pliegues infinitos de la materia y los pliegues del alma (Deleuze, 1988).

\section{El poder creativo de caminar}

Aunque podamos viajar con la imaginación mirando un mapa, al mover nuestro cuerpo nuestro viaje imaginario será mucho más prolífico. La cadencia rítmica del caminar acompaña y estimula la narrativa del pensamiento. Numerosos son los pensadores, escritores y artistas de todas las ramas que utilizan el caminar como proceso creativo, desde Montaigne a Rousseau, Kant, Nietzsche y tantos otros como recopila el libro de Frédéric Gros Marcher, une philosophie (2011).

En su último libro In Praise of Walking (2019), el investigador Shane 0'Mara, profesor de Investigación Experimental sobre el cerebro en el Trinity College de Dublín, explica por qué caminar impulsa el pensamiento creativo (cap. 7). Hay una extraña combinación en el caminar que mantiene unidas siempre dos realidades, espiritual y corporal. Mientras caminamos se activa el cuerpo y, al mismo tiempo, pensamos. Pero esto no es todo, sino que, además, al andar se facilita el alternar entre dos estados mentales diferentes: concentración y distracción. Según recientes estudios en psicología experimental nuestra mente necesita vagar para poder ser más eficiente. Concentrarse y distraerse son dos aspectos de una misma actividad cerebral, así como inspirar y espirar lo son en la respiración. El cerebro utiliza dos modalidades operativas, una activa ejecutiva y otra pasiva, el default mode 0 modo por defecto. La mente ejecutiva, funcional, operativa se concentra en los detalles y enfoca los problemas para encontrar soluciones. La mente pasiva se abstrae y se abandona a las ensoñaciones, vaga sin rumbo definido en el tiempo pasado y futuro, flota por zonas de límites desenfocados y presta poca o nula atención a lo que le rodea. Este vagabundear mental representa una fecunda incubación creativa y caminar la favorece particularmente, porque el mismo movimiento corporal, el vagabundear, acompaña físicamente el vagar mental. Al mismo tiempo, para no caernos, necesitamos prestar atención a dónde colocamos los pies. Caminar, por tanto, conlleva una continua alternancia entre distracción y concentración, lo que potencia la «oxigenación creativa» del cerebro.

Además, prosigue 0'Mara, hay un factor beneficioso para la actividad cerebral representado simplemente por el aumento de la actividad corporal. En cuanto ponemos nuestro cuerpo en movimiento, desencadenamos una serie de microdecisiones cerebrales que amplían y distribuyen la actividad cerebral conectando zonas neurológicas más alejadas entre sí. Esto aumenta la probabilidad de que afloren ideas dormidas en el umbral de la consciencia. Cuanto 


\section{artnodes}

https://artnodes.uoc.edu

El viaje in situ. De cómo el caminar en espacios confinados pueden potenciar la imaginación

más se estimulen las asociaciones remotas entre áreas cerebrales diferentes, más probable será el nacimiento de ideas insólitas e interesantes. Las investigaciones de Oppezzo y Swartz (2014) de la Universidad de Stanford -citadas por 0'Mara- demuestran que la capacidad de respuesta creativa a un problema es siete veces mayor cuando se camina, aunque sea sobre una cinta de caminar y en un ambiente aséptico totalmente privado de estímulos. Los autores también precisan que incluso desplazarse en silla de ruedas implica un suave ejercicio que podría tener efectos equivalentes sobre la creatividad. Concluyen que caminar es una estrategia muy eficiente y fácil de implementar para favorecer la generación de ideas creativas y recomiendan ponerla en práctica tanto en colegios como en puestos de trabajo.

\section{Conclusión: caminando hacia un nuevo paradigma}

Está claro que los efectos beneficiosos del caminar representan un recurso simple al alcance de todos, que estimula nuestro potencial creativo revelando el verdadero capital del ser humano: el poder de la imaginación. Este último fue el tema principal de la conferencia que impartió Didi-Huberman en el Centro José Guerrero de Granada (2019), titulada La imaginación, nuestra Comuna, un título realmente muy ocurrente en el que, por un lado, hace referencia a la Comuna de París (la revolución de 1871) -y, por tanto, al aspecto transformador de la imaginación- y, por otro, al «sentido común», es decir, a esta manera de percibir con los cinco sentidos que es común a todos los humanos y que es también la primera forma de conocimiento, la más inmediata, a la que se opondrá la racionalidad cartesiana. Para Aristóteles, dice Didi-Huberman, la sensación, la percepción de los cinco sentidos, era la fuente básica y primera del conocimiento. La palabra griega aisthesis significa «sensación» e indica a esa facultad sensitiva que organiza la información que nos envían los sentidos y que nos permite alcanzar lo que para Aristóteles era el conocimiento inmanente, la total unidad entre sujeto y objeto sensible. La teoría del «sentido común» evolucionó en los siglos posteriores hacia una teoría de la imaginación, siendo la imaginación esa facultad entre la sensibilidad y el intelecto, capaz de transformar las percepciones en imágenes (memoria) 0 ideas (intelecto). Tiene un absoluto potencial transformador, ya que vincula lo existente con lo posible. «Ahí donde el entendimiento hace normas y traza fronteras, la imaginación abre puertas y siempre está en movimiento», afirma Didi-Huberman.

Lo que nos indica esta relación entre la aesthesis griega y la estética contemporánea es que la imaginación está directamente relacionada con los cinco sentidos, con la inmersión en el mundo sensible y la atención que prestamos al mundo que nos rodea. El antropólogo Tim Ingold es un acérrimo defensor de la necesidad de volver a la atención, al contacto con el mundo en el que vivimos. Defiende que el verdadero problema ecológico en el que nos encontramos tiene su principal causa en la brecha entre mundo real y ciencia. «It's only when we acknowledge and recognize the presence of things before us that we can be curious about them» (Solo cuando reconocemos la presencia de las cosas ante nosotros podemos sentir curiosidad por ellas) (Ingold, 2017). Percibir la presencia en el mundo y de/ mundo despierta nuestra curiosidad y, a partir de ahí, arranca nuestra imaginación abriendo las puertas de los posibles.

El verdadero peligro se encuentra en el confinamiento voluntario que ejercemos cotidianamente recluyéndonos en un mundo virtual, pasando horas y horas delante de una pantalla, en el détachement (distanciamiento) de la tecnología que nos mantiene alejados del espesor real del mundo. Caminar y sentir nuestro cuerpo presente, aunque sea en un espacio limitado, despierta nuestra imaginación, el poder transformador de la realidad, recurso inextinguible de antialienación que tenemos siempre a nuestro alcance, si bien demasiado a menudo lo mantenemos anestesiado e inutilizado.

El confinamiento debido a la pandemia de COVID-19, aun con los problemas que conlleva, se ha revelado como un redescubrimiento tanto de nuestro cuerpo como del ambiente que nos rodea, dando lugar a un nuevo asombro por nuestro entorno y el mundo más cercano.

Quizás podría ser el inicio de un cambio de modelo de vida en el que, al retomar consciencia de nuestra corporalidad, volvamos a ver de cerca la realidad en la que vivimos y, a partir de ahí, a imaginar le «pas encore» (aún no), según la expresión de Ernst Bloch (Desroches, 2014), empezando a soñar, a «rêver como principio de rêvolution» (Valle Corpas, 2019). El confinamiento podría ser, entonces, no un encierro, sino una apertura, una pausa reflexiva, el «pensamiento periférico» de Kentridge que podría incubar una nueva idea 0 un nuevo paradigma de vida.

\section{Referencias bibliográficas}

Alÿs, Francis. 2014. Albert's way. https://francisalys.com/alberts-way/ Borges, José Luis. 2015. El Aleph. Barcelona: De Bolsillo.

Careri, Francesco. 2017. Walkscapes, el andar como práctica estética. Traducción de Maurici Pla. Barcelona: Gustavo Gili.

Careri, Francesco. 2020. «Careri/Valenzuela: Charlas sobre Espacio y Territorio». Youtube, abril 21, 2020. https://www.youtube.com/ watch?v=BFi00TCLtJo\&feature=emb_err_woyt.

Deleuze, Gilles. 1988. Le pli. Liebniz et le Baroque. Paris: Les Éditions de Minuit.

Desroches, Patricia. 2014. "Rêve et révolution». Cahiers de psychologie clinique 2014/1 (42): 209-227. https://www. cairn.info/publications-de-Patricia-Desroches--113048.htm. DOI: https://doi.org/10.3917/cpc.042.0209 


\section{artnodes}

Didi-Huberman, Georges. 2019. «La imaginación, nuestra Comuna». Abril 26. http://blogcentroguerrero.org/2020/07/georges-didihuberman-la-imaginacion-nuestra-comuna/. DOl: https://doi. org/10.30827/tnj.v3i2.13931

Gros, Frédéric. 2011. Marcher, une philosophie. Paris: Flammarion. Ingold, Tim. 2017. «The art of paying attention. Art of Research Conference. Youtube, November 29-30. https://www.youtube.com/ watch?v=2Mytf4ZSqQs\&t=3159s.

Kentridge, William. 2013. «Thinking on one's feet - a walking tour of the studio». Youtube, May 2013. https://www.youtube.com/ watch? $v=$ zhxACUiddhc.

Kentridge, William. 2017. «A Defence of the Less Good Idea». Youtube, May 30. https://www.youtube.com/watch?v=1YUqg1M0S5w.

Kitchen, Martin. 2015. Speer: Hitler's Architect. New Haven: Yale University Press.

Klee, Paul. 1960. Pedagogical Sketchbook. New York: Praeger Publishers.

Le Breton, David. 2000. Éloge de la marche. Paris: Éditions Métailié.

Le Breton, David. 2020. Marcher la vie. Paris: Éditions Métailié.

Maistre, Xavier de. 1829. Voyage autour de ma chambre. París: Librairie Delaunay. https://archive.org/details/voyageautourdem04maisgoog/page/n5/mode/2up
Moure, Gloria (ed.). 2014. On the road. Santiago de Compostela. Catalogue exhibition. Barcelona: SYL.

0'Mara, Shane. 2019. In Praise of Walking. The new science of how we walk and why it's good for us. London: Vintage. Kindle.

Oppezzo, Marily, y Schwarts, Damiel L. 2014. «Give Your Ideas Some Legs: The Positive Effect of Walking on Creative Thinking». Journal of Experimental Psychology: Learning, Memory and Cognition 40(4): 1142-1152. DOl: https://doi.org/10.1037/a0036577

Perec, Georges. 1989. L'infra-ordinaire. Paris: Éditions du Seuil.

Valle Corpas, Irene. 2019. «Goerges Didi-Huberman, imágenes que reparan». Blog del Guerrero, Mayo 22. https://blogcentroguerrero. org/2019/05/georges-didi-huberman-imagenes-que-reparan/.

Vila-Matas, Enrique. 2010. «El viaje alrededor». Babelia, El País. 2 enero, 2010. https://elpais.com/diario/2010/01/02/babelia/1262394757_850215.html.

Walkspace, 2020a. «About». http://walkspace.uk

Walkspace, 2020b. «Extreme Noticing under Lockdown, or how to launch a walking collective during a pandemic». https://vimeo. com/443903570.

Walkspace, 2020c. «Mapping Stirchley». http://walkspace.uk/ mapping-stirchley/. 


\section{artnodes}

https://artnodes.uoc.edu

El viaje in situ. De cómo el caminar en espacios confinados pueden potenciar la imaginación

\section{CV}

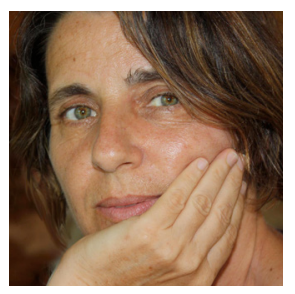

\section{Laura Apolonio}

Universidad de Granada. Facultad de Bellas Artes.

Departamento de Pintura

lauraapo@ugr.es; laura@equipocreativo.com

Artista multidisciplinar y diseñadora gráfica, vivió en diversos países de Europa (Italia, España, Francia, Suiza, Inglaterra), África (Somalia, Congo, Senegal, Argelia), América (EE.UU. y Venezuela) y Asia (Singapur). Creativa publicitaria en distintas agencias multinacionales de publicidad, directora de arte en una empresa líder de moda italiana (La Perla), fundadora de Equipo Creativo s.I. Su labor artística de carácter multidisciplinar abarca varios campos (dibujo, pintura, escultura, fotografía, vídeo), centrándose principalmente en el ámbito del arte en la naturaleza y la construcción de rutas y experiencias de arte en vivo. Pertenece al colectivo artístico En los Bordes, con el que ha realizado recientemente la ruta de obras en la naturaleza en La Zubia (Granada). Es docente-investigadora en la Facultad de Bellas Artes de la Universidad de Granada, donde, además de impartir docencia, realiza una labor de investigación y publicación de artículos sobre arte, diseño gráfico y estética. Su línea de trabajo está centrada en el espacio y en nuestra manera de habitarlo, la frontera entre el espacio interior y el exterior, entre lo urbano y lo natural, resumiéndose en las siguientes palabras claves: arte, cuerpo, espacio, caminar, estética.

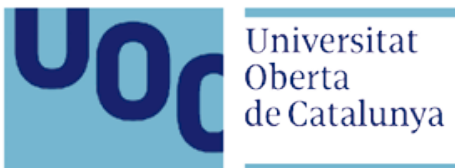

